\title{
クモ膜下出血後の脳血管攣縮の評価と血管内治療
}

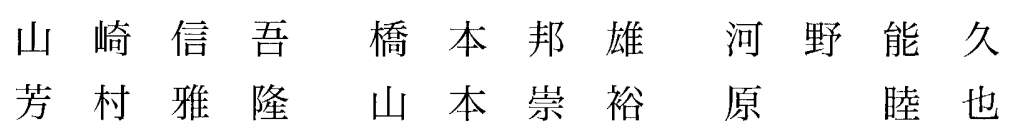

\section{Clinical Evaluation of Symptomatic Vasospasm after Aneurysmal Subarachnoid Hemorrhage and Patient Selection for Endovascular Treatments}

by

Shingo Yamasaki, M. D., Kunio Hashomoto, M. D., Yoshihisa Kawano, M. D., Masataka Yoshimura, M. D., Takahiro Yamamoto, M. D., and Mutsuya Hara, M. D.

from

Department of Neurosurgery, Tsuchiura Kyodo General Hospital

Efficacies of NIHSS in the evaluation of severity of symptomatic vasospasm (SVS) and in the selection of proper candidates for endovascular treatments (EVTs) against SVS were assessed. From 94 patients who developed SVS after the obliteration of a ruptured aneurysm in the acute periods during the past 8 years, outcomes and incidence of cerebral infarction were compared with the NIHSS scores before SVS and at the time of diagnosis of SVS between 28 cases treated before introduction of EVTs as standard therapeutic protocols and 46 cases that actually underwent EVTs. Furthermore, the efficacy of EVTs was examined between cases before ( 28 cases) and after ( 66 cases) introduction of EVTs, and the timing of EVTs were also assessed. The NIHSS before SVS tended to correlate with the development of cerebral infarction and with outcome in both groups, and NIHSS at the diagnosis correlated with both significantly. Patients after introduction of EVTs tended to have good outcomes, and patients who underwent EVTs within 6 hours from the diagnosis of SVS had better outcomes. From our results, sequential NIHSS scoring was useful in evaluating the severity of SVS and in selecting candidates for EVTs.

(Received July 11, 2005; accepted January 11, 2006)

Key words : subarachnoid hemorrhage, vasospasm, endovascular treatment, percutaneous transluminal angioplasty, papaverine, NIHSS

Jpn J Neurosurg（Tokyo） $15: 450-456,2006$

\section{緒 言}

脳血管攣縮が破裂脳動脈瘤治療後の転帰に影響する最 大の要素であることはいうまでもない1115)，血管攣縮予 防のためにさまざまな方法や薬剤が考案され導入されて きた。しかし，血管攣縮の発生率を減じることはできて も完全に予防することはできず，症候性血管攣縮 (SVS) は 20〜40\%の確率で合併している ${ }^{9) 15}$. SVS を合併する と約半数の症例で脳梗塞による後遺症を残すことになる ので, SVS の的確な診断・評価と治療が必要になる.
SVS に対する血管内治療 (EVTs) は, evidence based medicine（EBM）としては確立されてはいないが, EVTsに よる各種パラメータの改善や虚血症状の回復が多く報告 されてきている115) 8)14116)17)．報告では，SVS の評価や EVTs の適用は, 経頭蓋ドップラー検査 (TCD), MR angiography (MRA) や 3 dimensional CT angiography (3DCTA）などによることが多いが5(6)18)19)22)，これらの指標 が正確に SVS の重症度を表現できるかは疑問である。

一方, NIHSS は急性期脳虚血の重症度判定や転帰予測 において有用な評価法として確立され，さらには治療指

土浦協同病院脳神経外科 $/ \bar{\top} 300-0053$ 土浦市真鍋新町 11-7〔連絡先：山崎信吾〕

Address reprint requests to: Shingo Yamasaki, M. D., Department of Neurosurgery, Tsuchiura Kyodo General Hospital, 11-7 Manabeshinmachi, Tsuchiura-shi, Ibaraki 300-0053, Japan 
針の決定にも用いられている313)21). SVS は急性の脳虚 血であり, NIHSS がその評価法として有用な可能性があ る。本研究では，SVS の重症度判定および転帰予測にお けるNIHSS の有用性を評価しこれに基づいた EVTs 適 用の指針を検討した。 また, retrospective な研究ではあ るが，EVTs の有用性の評価や EVTs の適用タイミング についても検討を試みた。

\section{対象・方法}

1997〜2004 年までの 8 年間に, 当施設で発症から 48 時間以内に破裂脳動脈溜の治療を行った 307 例のうち 94 例がSVS を合併した. 当施設では 1999 年に SVS に対 するEVTs 導入しており，導入前の内科的治療のみを 行った 28 例を MT 群とし, 導入後の 66 例（R 群）中 EVTs を施行した 46 例を IVR 群とした。転州は, modified Rankin Scale (mRS) で退院時もしくは 3 力月後に評 価し，0〜2 点を転帰良好とし，3 点以上を転帰不良とし た。 また脳梗塞の合併は, 発症 4 週以降の $\mathrm{T} 2$ 強調画像 (T2WI) で評価した.

本研究の第一の目的は NIHSS による評価の妥当性の 検証であることから，SVS に対する治療法が異なる 2 群, すなわち MT 群と IVR 群への NIHSS の適用の有用 性を検討した。すなわち，SVS 発症前抒よび診断時の NIHSS 值と脳梗塞の合併頻度もしくは転帰とを, 内科的 治療例と EVTs 適用例のおのおので比較した。 また EVTs の有用性の検討に際しては， R 群のうち 20 例を適 用から外したことが bias のかかった患者選択にあたる 危険性を考慮し，導入後に実際には EVTsを施行しな かった症例を含めた $\mathrm{R}$ 群 66 例と MT 群 28 例の比較と した。さらには, EVTsの施行タイミングを推察するため に, SVS 発症から EVTs までの時間と脳梗塞合併率もし くは転帰を比較した。統計学的处理には $t$ 検定と $\chi^{2}$ 検 定, Mann-Whitney 検定を用いた。

\section{[1]破裂脳動脈瘤治療と SVS 予防}

当施設では，動脈瘤治療は開頭クリッピングを第一選 択としているが，307 例中 57 例にコイル塞栓術を施行, 38 例は神経症状もしくは全身状態が不良な症例で，19 例は脳底動脈溜であった。動脈瘤治療後はオザグレルナ トリウム $80 \mathrm{mg} /$ 日の投与と人工膠質液（6\%七ドロキシ エチルデンプン $500 \sim 1,000 \mathrm{ml}$ ) 投与による hemodilution/hypervolemia 治療を行っている，また，血腫量の多 い例と急性水頭症併存例にのみ脳槽ドレナージを留置し ている，血管攣縮の診断のコントロールとして，第 3 病
日までに 1 回, MRA と拡散強調画像（DWI）を撮影, その後スクリーニングとして 7 病日, 14 病日にも同様の 撮影を行った。無症候性の血管攣縮を診断した場合には， 人工膠質液を $1,500 \mathrm{ml} /$ 日まで増量し, チクロピジン $200 \mathrm{mg} /$ 日の投与を開始している.

神経症状は NIHSS を用いて 2〜4 時間ごとに評価，2 点以上悪化した場合に神経学的な畺化と判断した。CT で水頭症を除外した後に MRAもしくは 3D-CTA で $50 \%$ 以上の主幹動脈の狭窄，または末梢血管が描出され ない場合に SVS と診断した。

\section{SVS に対する EVTs（1999 年以降の症例）}

SVS を診断した際には，無症候性血管攣縮の診断時と 同様に hemodilution/hypervolemia 治療の強化を行い, 症 状が改善しないか悪化する場合には EVTs の適用を考慮 するが，DWIですでに広範囲の高信号域が存在した場合 にはEVTsの対象から外した。

EVTs はすべて十分な全身へパリン化，すなわち ACT 值を 250 秒以上もしくはコントロール值の 2 倍以上に 延長して行った。近位の血管（IC, M1〜M2, A1, VA, BA, P1〜P2) の攣縮に対しては経皮的血管形成術 (PTA) を，それよりも末梢の攣維に対して，もしくは近位でも バルーンカテーテルを進めることができなかった場合に は, 塩酸パパベリン動注 (IAP)を行った. PTA にはラテッ クス製の閉塞用バルーン (Equinox, Micro Therapeutic Inc, Irvin, CA）を用い, 塩酸パパベリンは生理的食塩水で $0.4 \%$ 溶液とし， $4 \mathrm{mg}$ /分の速度で, IC から注入する場合 には 80〜120 mgを, M1 からは $80 \mathrm{mg} を, \mathrm{~A} 1$ からは 40 $\mathrm{mg}$ を投与した.

\section{結 果}

IVR 群 46 例に, 延べ 55 回の EVTs（IAP 27 回, PTA 17 回, PTA + IAP 11 回) を適用し, 5 例に複数回の EVTs を施行した. EVTsによる合併症は 2 例で起こり， 2 例ともが IAP 後に出血性梗塞を合併，1例は脳死に 陥った。一方, PTA 施行による合併症は経験しなかった。 $\mathrm{R}$ 群のうち EVTs を適用しなかった 20 例は, SVS による 症状の自然緩解 9 例, DWI で EVTs 前に大きな梗塞巣が 描出された 4 例, 全身状態が不良な 5 例, ガイデイング カテーテルが留置できなかった 2 例である. 脳梗塞が理 由でEVTsの適用から除外した 4 例における，SVSによ る虚血症状の認識から DWI 撮影までの間隔は $4 \sim 12$ 時 間で， 6 時間以内が 3 例であった。 
Table 1 Summary of SVS cases before introduction of EVTs (MT group) and cases treated with EVTs (IVR group)

\begin{tabular}{|c|c|c|c|}
\hline & MT group & IVR group & $p$-value \\
\hline Period & Jan. 1997-Dec. 1998 & Jan. 1999-Dec. 2004 & \\
\hline Number of cases & 28 & 46 & \\
\hline Age (mean \pm standard deviation $)$ & $60.0 \pm 12.0$ & $61.0 \pm 12.5$ & $0.8134^{*}$ \\
\hline WFNS grade on admission & & & \\
\hline grade I - III & $17(60.7 \%)$ & $28(60.9 \%)$ & \\
\hline grade IV & $8(28.6 \%)$ & $13(28.3 \%)$ & $0.9739^{* *}$ \\
\hline grade $\mathrm{V}$ & $3(10.7 \%)$ & $5(10.9 \%)$ & \\
\hline Neck clipping: Embolization & $24: 4$ & $39: 7$ & $0.9130^{* *}$ \\
\hline Number of cases that underwent EVTs & & & \\
\hline IAP & - & 19 & \\
\hline PTA & - & 16 & \\
\hline PTA + IAP & - & 11 & \\
\hline NIHSS before SVS & $5.000 \pm 3.333$ & $4.804 \pm 3.733$ & $0.8158^{*}$ \\
\hline NIHSS at SVS onset & $14.079 \pm 6.080$ & $13.043 \pm 6.215$ & $0.4430^{*}$ \\
\hline
\end{tabular}

Summary of cases before the introduction of endovascular treatments (EVTs) for symptomatic vasospasm (SVS) (MT group) and cases that underwent EVTs (IVR group). For satistical analysis, the $t^{- \text {test }}\left({ }^{*}\right)$ and chi-square test $(* *)$ are used.
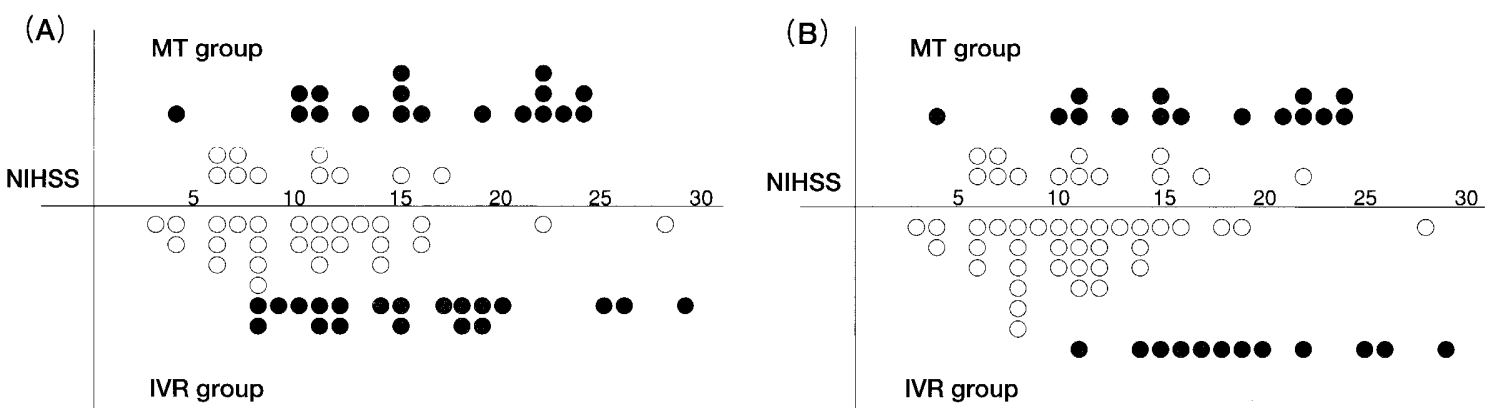

Fig. 1 Graphs show the relation between NIHSS and cerebral infarction (A) and outcome (B). Black circles show cases developed cerebral infarction (A) or cases with poor outcomes (B), and white circles show cases without cerebral infarction $(\mathbf{A})$ or cases with good outcomes $(\mathbf{B})$.

Table 2 Comparison of NIHSS scores and incidence of cerebral infarction or outcome

\begin{tabular}{|c|c|c|c|c|c|c|}
\hline & & $n$ & $\begin{array}{c}\text { NIHSS scare } \\
\text { before SVS } \\
\text { (mean } \pm \text { standard } \\
\text { deviation) }\end{array}$ & $p$-value & $\begin{array}{l}\text { NIHSS score at } \\
\text { SVS onset } \\
\text { (mean } \pm \text { standard } \\
\text { deviation) }\end{array}$ & $p$-value \\
\hline MT group & $\begin{array}{l}\text { Cerebral Infarction }(-) \\
\text { Cerebral Infarction }(+)\end{array}$ & $\begin{array}{l}10 \\
18\end{array}$ & $\begin{array}{l}4.100 \pm 2.998 \\
5.500 \pm 3.485\end{array}$ & 0.2769 & $\begin{array}{l}10.000 \pm 3.859 \\
16.500 \pm 5.904\end{array}$ & 0.0017 \\
\hline IVR group & $\begin{array}{l}\text { Cerebral Infarction }(-) \\
\text { Cerebral Infarction }(+)\end{array}$ & $\begin{array}{l}26 \\
20 \\
\end{array}$ & $\begin{array}{l}4.296 \pm 3.550 \\
9.798 \pm 0.287\end{array}$ & 0.2866 & $\begin{array}{l}11.111 \pm 5.767 \\
14.061 \pm 5.912 \\
\end{array}$ & 0.0111 \\
\hline MT group & $\begin{array}{l}\text { Good Outcome }(\operatorname{mRS} 0 \sim 2) \\
\text { Poor Outcome }(\operatorname{mRS} 3 \sim 6)\end{array}$ & $\begin{array}{l}13 \\
15\end{array}$ & $\begin{array}{l}3.769 \pm 2.833 \\
6.067 \pm 3.453\end{array}$ & 0.0642 & $\begin{array}{l}11.308 \pm 4.837 \\
16.667 \pm 6.079\end{array}$ & 0.0154 \\
\hline IVR group & $\begin{array}{l}\text { Good Outcome }(\operatorname{mRS} 0 \sim 2) \\
\text { Poor Outcome } \quad(\operatorname{mRS} 3 \sim 6)\end{array}$ & $\begin{array}{l}34 \\
12 \\
\end{array}$ & $\begin{array}{l}4.029 \pm 3.109 \\
7.000 \pm 4.573\end{array}$ & 0.0550 & $\begin{array}{l}10.824 \pm 4.871 \\
19.333 \pm 5.331\end{array}$ & $<0.0001$ \\
\hline
\end{tabular}

The NIHSS scores before onset of symptomatic vasospasm (SVS) tend to correlate with outcome, and the NIHSS at SVS onset correlated well with the development of cerebral infarction and with outcome. For satistical analysis, the $t$-test is used. 
Table 3 Comparison of cases before（MT group）and after（R group）introduction of EVTs for SVS

\begin{tabular}{|c|c|c|c|}
\hline 1 & MT group & $\mathrm{R}$ group & $p$-value \\
\hline Period & Jan. 1997-Dec. 1998 & Jan. $1999-$ Dec. 2004 & \multirow{4}{*}{$0.8634^{*}$} \\
\hline Number of cases & 28 & 66 & \\
\hline Age (mean \pm standard deviation) & $60.0 \pm 12.0$ & $61.5 \pm 11.6$ & \\
\hline WFNS grade on admission & & & \\
\hline grade I-III & $17(60.7 \%)$ & $41(62.1 \%)$ & \multirow{3}{*}{$0.8684^{* *}$} \\
\hline grade IV & $8(28.6 \%)$ & $16(24.2 \%)$ & \\
\hline grade $\mathrm{V}$ & $3(10.7 \%)$ & $9(13.6 \%)$ & \\
\hline Neck clipping : Embolization & $24: 4$ & $56: 10$ & \multirow[t]{2}{*}{$0.9141 * *$} \\
\hline Number of cases that underwent EVTs & 0 & 46 & \\
\hline NIHSS before SVS & $5.000 \pm 3.333$ & $4.863 \pm 4.321$ & $0.8691^{*}$ \\
\hline NIHSS at SVS onset & $14.079 \pm 6.080$ & $13.106 \pm 6407$ & $0.4449^{*}$ \\
\hline Cases that developed cerebral infarction & $18(64.3 \%)$ & $33(50.0 \%)$ & $0.2630^{* *}$ \\
\hline Modified Rankin Scale mean score & 2.96 & 2.18 & $0.1503^{* * *}$ \\
\hline $0 \sim 2$ (good outcome) & 13 cases & 45 cases & \multirow{2}{*}{$0.0472^{* *}$} \\
\hline $3 \sim 6$ (poor outcome) & 15 cases & 21 cases & \\
\hline
\end{tabular}

Outcome of cases with SVS tentds to improve with the introduction of EVTs. For satistical analysis, the $t$-test $\left({ }^{*}\right)$, chi-square test $(* *)$ and Mann-Whitney U-test $(* * *)$ are used.

Fig. 2 Graphs show the timing of endovascular treatments (EVTs) and the chance of cerebral infarction (upper) and outcomes (lower). Earlier application of EVTs decreased the chance of cerebral infarction and poor outcomes. For satistical analysis, the chi-square test is used.

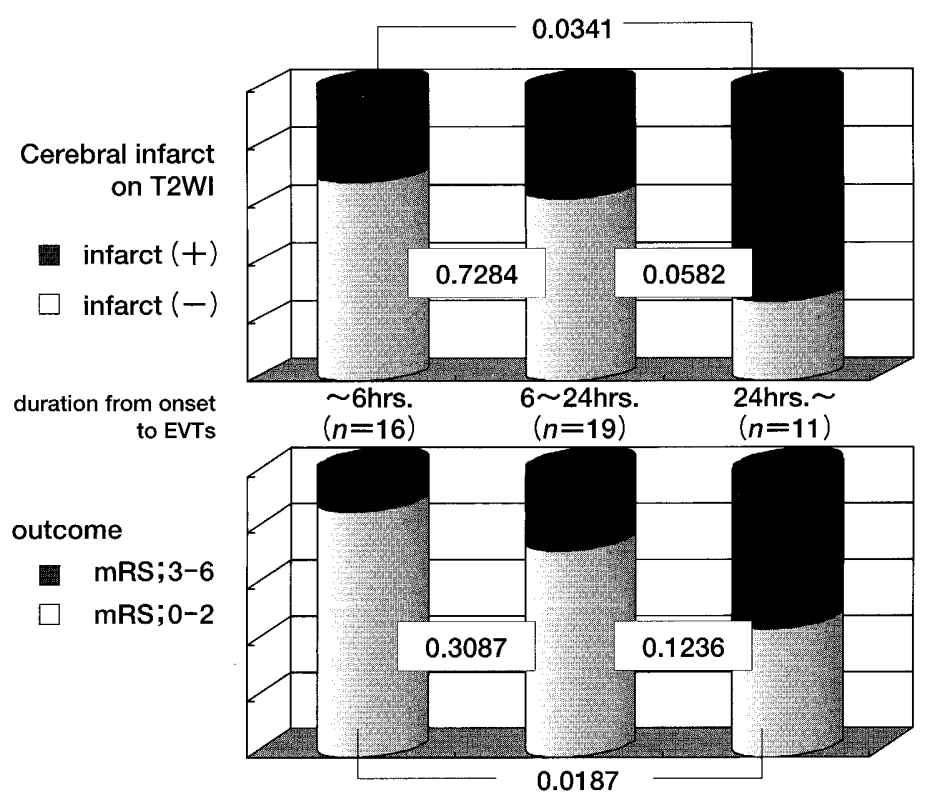

\section{T2WI 上の脳梗塞}

MT 群とIVR 群の年齢, WFNS grade, 動脈瘤の治療 法やSVS 発症前と発症時の NIHSSに差がなかった (Table 1). MT 群と IVR 群の T2WI 上での脳梗塞の合併 は，おのおの 18 例 $(64.3 \%), 20$ 例 (43.5\%) であった. Fig. 1 の上段は MT 群と IVR 群の SVS 発症時の NIHSS を plot したもので, 而群ともに 10 点以上で合併例が多 い印象があった。 NIHSS と脳梗塞の合併を比較すると, SVS 発症前の NIHSS は両群ともに脳梗塞合併例と非合 併例の間に差はなかったが, SVS 発症時の NIHSS は脳梗 塞合併例で有意に高かった（Table 2).

\section{2. 転帰}

SVS 発症前の NIHSS は, MT 群, IVR 群両群ともで有 意差はなかったものの，転帰不良例が転帰良好例に比し て高い傾向があった（Table 2)。一方, SVS 診断時の NIHSS は, 有意に転州と相関した。転帰と SVS 診断時の NIHSS をプロットした Fig. 1 下段をみると, MT 群, IVR 群ともに 10 点以上で転㷌不良例が目立った。また, EVTs の適用を考慮するべき NIHSS score を推測すべく MT 群について $\chi^{2}$ 検定を行ったところ, 13 点以上の症例 では 12 点以下に比して有意に転帰不良例が多かった $(p=0.0243)$. 


\section{EVTs の有用性}

MT 群と R 群の, 年㱓などの SVS 発症までの諸要素に 差はなく (Table 3), 脳梗塞の合併率は $64.3 \%$ と $50.0 \%$ と ほぼ同様であった。 $\mathrm{mRS}$ の平均值は, MT 群の 2.96 に 対し R 群は 2.18 と低い傾向があったが, Mann-Whitney 検定では有意差はなかった $(p=0.1503)$ 。しかし, mRS 2 点と 3 点の間で転帰良好・不良例に分けて $\chi^{2}$ 検定を 行うと, $\mathrm{R}$ 群の転帰が有意に良好であった $(p=0.0472)$.

\section{EVTs のタイミング}

SVS の診断から EVTs までの時間は 1 時間半から 72 時間で, 平均 16.3 時間であった。 $\mathrm{mRS} 0 \sim 2$ 点の転帰良 好例では平均 12.2 時間で, 3 6 点の転帰不良例では 21.8 時間で, 前者が短い傾向があったが, 有意差はな かった ( $p=0.138)$. IVR 群を, 6 時間未満 16 例, 6 時間 以上 24 時間未満 19 例, 24 時間以降 11 例の 3 群に分け て脳梗塞合併率と転帰を比較した（Fig. 2). 脳梗塞の合 併率・転帰不良となる確率は，EVTs までの時間が長い 例で高くなる傾向があり, 6 時間未満の施行例は 24 時間 以降の施行例よりも有意に低かった $(p=0.341$ と 0.0187).

\section{考 察}

過去の多くの文献で SVS に対するPTA の有用性が報 告されてきており, 組織病理学的研究もこれを支持して いる1024). しかし，血管造影上の改善が約 $90 \%$ の例で得 られるのに対して, 神経症状が改善するのは $60 \sim 70 \% に$ 過ぎず，両者の間には相当の差異がある7)8)16)17720)。この 差異を生じる要因としては，(1)SVSによる虚血性侵襲に 対する脳の而性, (2)PTA の対象とならない細血管や末梢 血管の攣縮の有無やその程度 ${ }^{24)}$, (3)SVS の発症から PTA までの時間などが挙げられる。一方，IAP の有用性につ いては論議のあるところであるが4(6)12) 14)17720), PTA の対 象にならない末梢部や穿通枝に対しては，血管拡張作用 を有する薬剤の局所投与しか選択肢がないのが現状であ り，両者は相互に補完的な関係にあると考えられるので， 両者を合わせて EVTs として扱った。

血管造影上の血管攣縮の頻度がSVS よりも高いこと

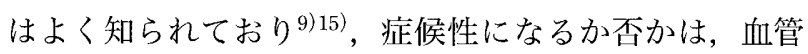
攣縮の範囲や程度の他に，虚血性侵襲に対する脳の耐性 が関与すると考えられ，症候性になることはある意味で 脳の代償能の破綻を意味すると考えられる. Higashida $ら^{8)}$ や Zubkov ら ${ }^{23)}$ は，SVS に対するPTA 後の神経症状 の回復は Hunt and Hess grade，すなわちクモ膜下出血 （SAH）による侵襲の程度がその後の合併症である SVS
からの回復に影響することを示唆している.SVS 前の脳 の状態，虚血に対する耐性は，SAHのみならず動脈瘤治 療も関与すると考元, SVS 発症前の神経症状の評価を行 い転帰と比較したところ, 統計学的な有意差は得られな かったものの相関する傾向がみられた。

-一方, SVS の重症度の判定には, これまで血行動態の 評価, すなおち $\mathrm{TCD}$ や脳血流量, 定量的な $\mathrm{DSA}^{5 / 6) 17) 22)}$ などが報告されてきて㧍り, 特に TCDによる評価が確 立されている。しかし，これらの指標はあくまで一要素 による評価であり，総和的に神経症状を評価することが SVS の重症度判定においてょり適切であると考える. 神 経症状を数值化・定量化するにあたって, SVS が急性脳 虚血であることから，脳虚血急性期の評価法として確立 されているNIHSS を今回採用した，NIHSS は検者によ る差異が少なく, 比較的簡単に使用でき, 特別な機器が 不要であるという利点があり，その正確さには一定の評 価がある313321). 今回の検討では, SVS 発症時の NIHSS score は, 内科的治療例および EVTs 施行例の両群で有意 に脳梗塞の合併や転帰と相関した.

今回の検討は randamized study ではないので, 厳密に はEVTs の有用性の検証はできないが，EVTs 導入前の 保存的治療群よりも EVTs 導入後の症例の転帰が良い傾 向があり, 適切な EVTs の適用の必要性が示唆された。 EVTs の適用については, 無症候性の血管攣縮に対して も予防的に PTA を行うという報告もあるが ${ }^{122}$, SVS の自 然緩解もしくは保存的治療での改善がみられる例が半数 近く認められること,EVTs の有用性が EBM として確立 されていないことやEVTsに合併症の危険性 ${ }^{6 / 8) 12) 14) か ゙ ~}$ あることから，何らかの基準が必要である. PTA 適用の 患者選択の基準として, TCD の中大脳動脈（MCA）流 速值による判断が推奨されているが55), 前述した理由で 神経症状による判断のほうが的確ではないかと考兄られ る.保存的治療では NIHSS score が 13 点以上で有意に転 帰不良であったが, NIHSS score と転帰を plot した Fig. 1 からは, 安全策として 10 点以上の症例には積極的に EVTs を適用するべきであると考元られる。すなわち， SVS 診断時に NIHSS score が 10 点以上の例や経過中に 10 点以上になった例では, EVTsの適用が好ましいと思 わ机る。

SVS に対するEVTs の適用のタイミングについては， 転帰とは相関しないという報告1)がある一方, SVS 発症 から早期の適用，すなわち 2 3 時間以内 ${ }^{2)}, \quad 12 \sim 18$ 時

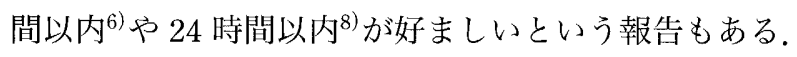
今回の検討では 6 時間以内の適用が好ましく, 時間経過 とともに転帰不良例が増える傾向があったこと, EVTs 
を施行できなかった症例の中には診断から 6 時間以内 に広範な梗塞巣が完成した例が存在することから, 速や かな適用が重要である。 Eskridge ら5) 疇の中に, 最大限の保存的治療により症状が改善しない ことが条件になっているが, 保存的治療による経過観察 が時間を浪費し，“therapeutic window”を逸する危険性 を孕んだ症例が存在することは間違いないと考えられ る. 今回の検討からは, 保存的治療では危険性が高く, 速やかな EVTs の適用が必要な症例を選択するうえで NIHSS による評価が有用であると考えられ, SVS 診断時 の NIHSS score10 点以上の症例がこれに該当すると考察 された。

SVS に対するEVTsの適用の判断において, 神経症状, すなわち機能的な評価が重要なことは前述してきたとお りであるが，形態的な評価が必須であることはいうまで もない. EVTs の適用については, DWI による脳梗塞の除 外と MRA での血管攣縮の証明が有用であり, NIHSS score の悪化時には MRI/MRA を可及的速やかに施行す る必要があると考える，ただし，MRAでは血腫の影響 で血管径の診断が不正確になる場合があるので，3DCTA の併用も考慮するべきである。

\section{結 語}

今回の検討で, SVS の重症度評価におけるNIHSS の有 用性を示した，EVTs の適用に際してはNIHSSによる評 価が有用であり, SVS 診断時に 10 点以上もしくは経過 中に 10 点以上になる症例では速やかな, 6 時間以内の EVTs の施行が肝要である.

\section{文 献}

1) Bejjani GK, Bank WO, Olan WJ, Sekher LN: The efficacy and safety of angioplasty for cerebral vasospasm after subarachnoid hemorrhage. Neurosurgery 42:979-987, 1998.

2) Brothers MF, Holgate RC: Intracranial angioplasty for treatment of vasospasm after subarachnoid hemorrhage: Technique and modifications to improve branch access. AJNR Am J Neuroradiol 11: 239-247, 1990.

3) Brott T, Adams HP, Olinger CP, Marler JR, Barsan WG, Biller J, Spilker J, Holleran R, Eberle R, Hertzberg V, Rorick M, Moomaw CJ, Walker M: Measurements of acute cerebral infarction: A clinical examination scale. Stroke $20: 864-870,1989$.

4) Clouston JE, Numaguchi Y, Zoarski GH, Aldrich EF, Simard JM, Zitnay KM: Intraarterial papaverine infusion for cerebral vasospasm after subarachnoid hemorrhage. AJNR Am J Neuroradiol $\quad$ 16: 27-38, 1995.

5) Eskridge JM, Newell DW, Winn HR: Endovascular treatment of vasospasm. Neurosurg Clin N Am 5:437-447,
1994.

6) Eskrigde JM, Song JK : A practical approach to the treatment of vasospasm. AJNR Am J Neuroradiol 18:16531660, 1997.

7) Fujii $Y$, Takahashi A, Yoshimoto $T$ : Effect of balloon angioplasty on high grade symptomatic vasospasm after subarachnoid hemorrhage. Neurosurg Rev 18:7-13, 1995.

8) Higashida RT, Halbach VV, Dowd CF, Dormandy B, Bell J, Hieshima GB: Intravascular balloon dilatation therapy for intracranial arterial vasospasm: Patient selection, technique, and clinical results. Neurosurg Rev 15:89-95, 1992.

9) Hoh BL, Topcuoglu MA, Singhal AB, Pryor JC, Ravinov JD, Rordorf GA, Carter BS, Ogilvy CS : Effect of clipping, craniotomy, or intravascular coiling on cerebral vasospasm and patient outcome after aneurismal subarachnoid hemorrhage. Neurosurgery $\mathbf{5 5}:$ 779-789, 2004.

10) Honma Y, Fujiwara T, Irie K, Ohkawa M, Nagao S: Morphological changes in human cerebral arteries after percutaneous transluminal angioplasty for vasospasm caused by subarachnoid hemorrhage. Neurosurgery $36:$ 1073-1081, 1995.

11) Kassell NF, Torner JC, Haley EC, Jane JA, Adams HP, Kongable GL: The international cooperative study on the timing of aneurysmal surgery. Part 1: Overall management results. J Neurosurg 73: 18-36, 1990.

12) Katoh H, Shima K, Shimizu A, Takiguchi H, Miyazawa T, Umezawa H, Nawashiro H, Ishihara S, Kaji T, Makita K, Tsuchiya $\mathrm{K}$ : Clinical evaluation of the effect of percutaneous transluminal angioplasty and intra-arterial papaverine infusion for the treatment of vasospasm following aneurysmal subarachnoid hemorrhage. Neurol Res 21: 195-203, 1999.

13) Lyden PD, Lu M, Levine SR, Brott TG, Broderick J : A modified National Institutes of Health Stroke Scale for use in stroke clinical trials. Preliminary reliability and validity. Stroke 32: 1310-1317, 2001.

14) Mathis JM, Jesen ME, Dion JE : Technical considerations on intra-arterial papaverine hydrochloride for cerebral vasospasm. Neuroradiology 39: 90-98, 1997.

15) Mayberg MR: Intracranial arterial spasm. in Wilkins RH, Rengachary SS (eds) : Neurosurgery 2nd ed, vol. II. New York, McGraw-hill, 1996, p.2254.

16) Newell DW, Eskridge JM, Mayberg MR, Grady MS, Winn HR: Angioplasty for the treatment of symptomatic vasospasm following subarachnoid hemorrhage. $J$ Neurosurg 71: 654-660, 1989.

17) Oskourian RJ, Martin NA, Lee JH, Glenn TC, Guthrie D, Gonzalez NR, Afari A, Vinuela F : Multimodal quantitation of the effects of endovascular therapy for vasospasm on cerebral blood flow, transcranial doppler ultrasonographic velocities, and cerebral artery diameters. Neurosurgery 51:30-43, 2002.

18) Takagi R, Hayashi H, Kobayashi H, Kumazaki T, Isayama $\mathrm{K}$, Ikeda $\mathrm{Y}$, Teramoto A : Three-dimensional CT angiography of intracranial vasospasm following subarachnoid hemorrhage. Neuroradiology 40:631-635, 1998.

19) Tamatani S, Sasaki O, Takeuchi S, Fujii $Y$, Koike T, Tanaka $\mathrm{R}$ : Detection of delayed cerebral vasospasm, after rupture of intracranial aneurysms, by magnetic resonance angiography. Neurosurg $\quad 40: 748-754,1997$. 
20) Terada T, Kinoshita $Y$, Yokote $H$, Tsuura $M$, Nakai K, Itakura T, Hyotani G, Kuriyama T, Naka Y, Kido T: The effect of endovascular therapy for arterial spasm, its limitation and pitfalls. Acta Neurochir (Wien) 139;227-234, 1997.

21) Tong DC, Yenari MA, Albers GW, O'Brien M, Marks MP, Moseley ME: Correlation of perfusion-and diffusionweighted MRI with NIHSS score in acute $(<6.5$ hour) ischemic stroke. Neurology $\quad 50: 864-870,1998$.
22) Touho $\mathrm{H}$ : Hemodynamic evaluation with dynamic DSA during the treatment of cerebral vasospasm: A retrospective study. Surg Neurol 44:63-74, 1995.

23) Zubkov YN, Alexander LF, Smith RR, Benashvili GM, Semenyutin V, Bernanke D : Angioplasty of vasospasm : Is it reasonable? Neurol Res 16:9-11, 1994.

24) Zubkov AY, Lewis AI, Scalzo D, Bernanke DH, Harkey HL : Morphological changes after percutaneous transluminal angioplasty. Surg Neurol 51 : 399-403, 1999.

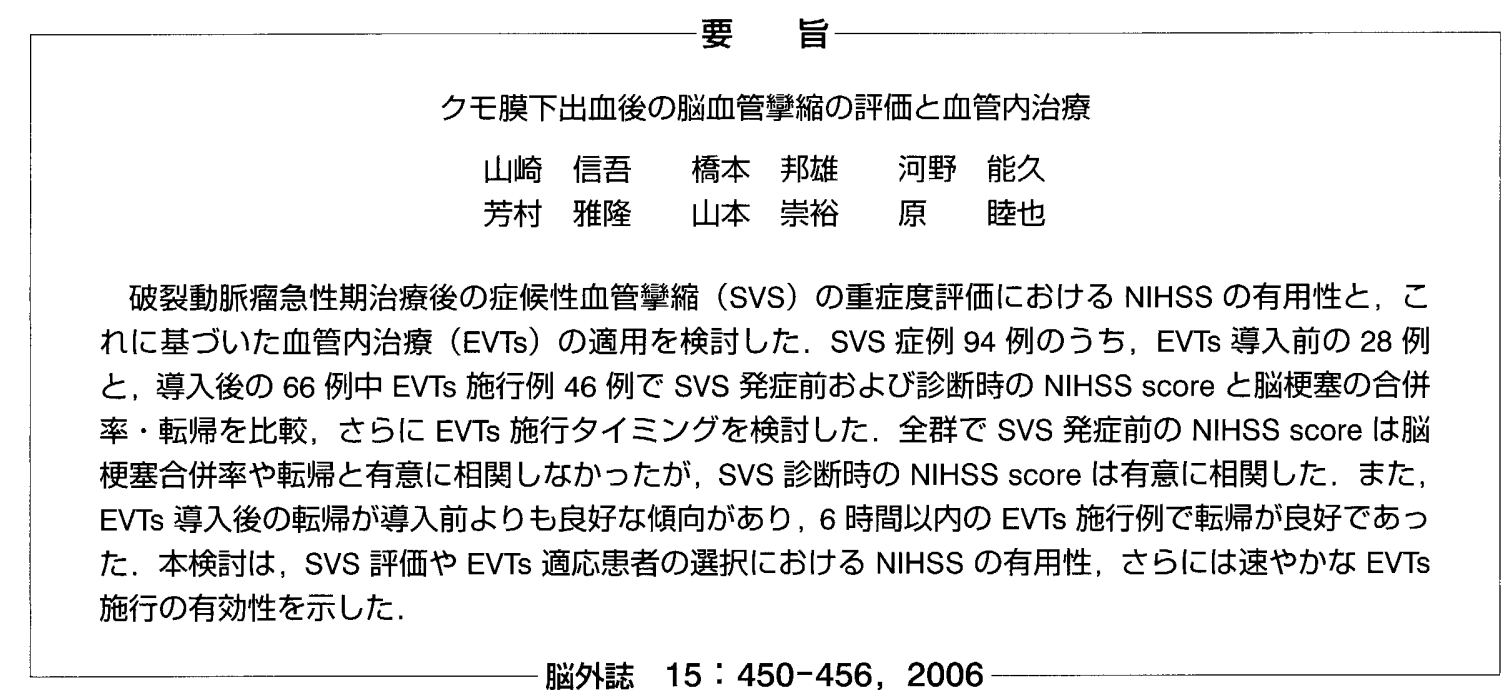

